\title{
PENGARUH MOTIVASI DAN KEPUASAN TERHADAP KINERJA KARYAWAN PEMASARAN PERBANKAN SYARIAH DI KABUPATEN SUMENEP
}

\author{
Nurlaily Wulandari ${ }^{1}$, Alvin Arifin ${ }^{2}$, RA. Istiqomah Pujiningtiyas ${ }^{3}$, Moh. Arifin ${ }^{4} \&$ \\ Masfufatul Khoiriyah ${ }^{5}$ \\ 1,2,3,4\&5 Universitas Bahaudin Mudhary Madura \\ Email:n_wulandari999@unibamadura.ac.id,alvinarifin@unibamadura.ac.id. \\ istiqomah.student@unibamadura.ac.id,moharifin.student@unibamadura.ac.id, \\ masfufatulkhoiriyah.student@unibamadura.ac.id
}

\begin{abstract}
ABSTRAK
Tujuan dari penelitian ini adalah untuk mengetahui pengaruh motivasi dan kepuasan terhadap kinerja karyawan. Objek penelitian ini adalah karyawan pemasaran perbankan Syariah di Kabupaten Sumenep. Populasi keseluruhan karyawan bagian pemasaran perbankan syariah dengan teknik sampling yang digunakan adalah accidental sampling sebanyak 32 karyawan yang ditemui. Jenis penelitian ini adalah penelitian kuantitatif yang menyajikan data secara statistik. Analisis yang digunakan adalah analisis regresi yang bertujuan untuk menguji pengaruh antar variabel dengan beberapa tahapan yaitu: pertama, uji deskriptif yang membuktikan bahwa karyawan laki-laki > karyawan perempuan dengan perbandingan 17:15, sedangkan karyawan dengan usia dibawah 20 tahun < karyawan dengan usia diatas 20 tahun dengan perbandingan 13:19, kemudian karyawan dengan gaji dibawah Rp. 500,000 < karyawan dengan gaji diatas Rp. 500,000 dengan perbandingan 11:21. Kedua, uji validitas menunjukkan bahwa keseluruhan instrumen penelitian menunjukkan hasil yang valid. Ketiga, Uji regresi masing-masing variabel menunjukkan bahwa motivasi berpengaruh positif dan signifikan terhadap kinerja. Keempat, Uji regresi berganda yang menunjukkan bahwa kepuasan dan motivasi berpengaruh positif dan signifikan terhadap kinerja. Dari keempat tahapan tersebut membuktikan bahwa kedua variabel motivasi dan kepuasan berpengaruh positif dan signifikan terhadap variabel kinerja.
\end{abstract}

Kata kunci : Motivasi, Kepuasan, Kinerja

\begin{abstract}
The purpose of this study was to determine the effect of motivation and satisfaction on employee performance. The object of this research is the marketing employees of Islamic banking in Sumenep Regency. The total population of employees of the marketing division of Islamic banking with the sampling technique used was accidental sampling, as many as 32 employees were met. This type of research is a quantitative study that presents statistical data. The analysis used is regression analysis which aims to examine the effect between variables with several stages, namely: first, descriptive test which proves that male employees > female employees with a ratio of 17:15, while employees under 20 years < employees with above age 20 years with a ratio of 13:19, then employees with salaries below Rp. 500,000 < employees with salaries above Rp. 500,000 with a ratio of 11:21. Second, the validity test shows that the entire research instrument shows valid results. Third, the regression test for each variable shows that motivation has a positive and significant effect on performance. Fourth, multiple regression test which shows that satisfaction and motivation have a positive and significant effect on performance. From the four stages, it proves that the two variables of motivation and satisfaction have a positive and significant effect on the performance variable
\end{abstract}

Keywords : Motivation, Satisfaction, Performance. 


\section{PENDAHULUAN}

Kinerja merupakan hasil dari pekerjaan karyawan yang telah dilakukan. Kinerja juga dapat berupa kontribusi yang dinilai kemudian mendapat timbal balik dari perusahaan. Kinerja penting bagi perusahaan sebagai jalan untuk menggapai tujuan yang telah direncanakan.

Salah satu cara untuk melihat kemajuan kinerja suatu organisasi adalah dengan mengevaluasi pegawai dalam organisasi tersebut. Penilaian dapat dilakukan terhadap karyawan dan manajer. Sistem penilaian menggunakan metode yang dianggap paling sesuai dengan bentuk organisasi, karena penyalahgunaan metode akan membuat penilaian yang dilakukan tidak dapat memberikan jawaban yang diinginkan (Adam \& Kamase, 2019).

Motivasi berperan sangat penting dalam mempengaruhi tingkat kemampuan dalam menjalankan fungsinya, sehingga suasana yang harmonis dapat mendorong prestasi kerja. Selain motivasi, kepuasan kerja juga harus menjadi perhatian perusahaan karena kepuasan kerja merupakan perasaan senang atau senang seseorang sebelum dan sesudah melakukan suatu pekerjaan. Jika karyawan merasa senang dalam bekerja, maka hasil pekerjaannya akan bagus. Begitu pula jika seseorang tidak senang dalam pekerjaannya, maka akan berpengaruh pula pada pekerjaan karyawan. Dengan demikian, kepuasan kerja dapat mempengaruhi kinerja (Kelimeda, Hairudinor, Ridwan, \& Dalle, 2018).

Pemberian dorongan berupa motivasi sangat diperlukan untuk meningkatkan semangat kerja karyawan sehingga mampu mencapai hasil yang diinginkan oleh manajemen. Hubungan antara motivasi, moral dan hasil yang optimal dalam arti memiliki bentuk linier dengan pemberian motivasi yang baik untuk bekerja, maka moral karyawan akan meningkat dan pekerjaan akan lebih optimal sesuai dengan standar kinerja yang ditetapkan (Palar, 2016).

Kunci untuk memotivasi karyawan adalah untuk mengetahui apa yang memotivasi mereka dan merancang program motivasi berdasarkan kebutuhan tersebut (Cong \& Van, 2013). Kepuasan kerja menggambarkan seberapa puas seseorang dengan pekerjaannya. Kepuasan kerja sering kali dianggap sebagai keadaan emosi yang menyenangkan atau positif hasil dari evaluasi atau penilaian pekerjaan atau pengalaman kerja (Pang \& $\mathrm{Lu}, 2018$ ).

Kepuasan juga menggambarkan bagaimana perasaan karyawan tentang pekerjaan mereka karena dipengaruhi oleh banyak orang faktor eksternal. Kepuasan kerja sebagai kombinasi apapun psikologis, fisiologis dan keadaan lingkungan yang menyebabkan orang yang dengan jujur mengatakan bahwa dia puas dengan pekerjaannya. Apalagi tidak ada definisi pekerjaan yang diterima secara universal kepuasan karena itu kompleks dan konsep multifaset yang memberikan perbedaan (Jr, 2016)

Kepuasan kerja yang diamati menghasilkan sentimen progresif di antara individu-individu yang secara kasual menandakan balasan emosi yang optimis ke arah keinginan akan otoritas. Penulis juga membahas lebih lanjut bahwa kepuasan dicapai karena orang yang memahami pentingnya standar kerja untuk mencapai kebutuhan dasar seseorang. Bagi individu yang memiliki kemampuan orientasi kerja tinggi, kepuasan kerja merupakan salah satu faktor penting..

\section{TINJAUAN PUSTAKA}

Kinerja adalah hasil yang diperoleh suatu organisasi baik organisasi itu adalah profit berorientasi dan nonprofit oriented yang diproduksi selama periode 
waktu. Kinerja tingkat tinggi adalah hasil dari melakukan sesuatu dengan benar di waktu yang tepat. Kinerja yang efektif dalam pekerjaan adalah hasil yang tepat, atau sesuatu yang benar untuk pekerjaan tertentu pada waktu tertentu. Kinerja kinerja sangat dipengaruhi oleh faktorfaktor berasal dari pekerja itu sendiri yang dipengaruhi oleh kemampuan atau kompetensi mereka, serta yang bersumber organisasi yang dipengaruhi oleh seberapa baik pemimpin memberdayakan pekerjanya, bagaimana memberi penghargaan kepada karyawan dan bagaimana caranya membantu meningkatkan kemampuan kinerja pekerja (Adam \& Kamase, 2019).

Aspek-aspek yang dinilai dalam penilaian kinerja adalah kuantitas hasil, kualitas hasil, ketepatan waktu hasil, ketepatan waktu, kehadiran, kemampuan bekerja sama (Aryanta, Sitiari, \& Yasa, 2019). Menghadapi persaingan lingkungan global yang ketat, organisasi harus terus mengembangkan inovasi dan kemampuan untuk maju (Saryadi \& Arini, 2019).

Indikator kinerja (Bhatti, Awan, \& Razaq, 2014): 1) Kuantitas, yaitu pekerjaan yang dihasilkan sesuai dengan tugas yang dibebankan, 2) Kualitas, yaitu pekerjaan yang dihasilkan memiliki mutu yang baik, 3) Berkontribusi dalam tim, yaitu ikut andil dalam pekerjaan yang dilakukan secara tim. 4) Akomodatif dan kooperatif, yaitu dapat diajak bekerja sama. 4) Tepat waktu, yaitu dalam menyelesaikan pekerjaan sesuai dengan waktu yang ditentukan.

Motivasi merupakan rangsangan penting yang mengarahkan perilaku manusia. Tidak ada individu yang sama sikap atau perilaku, maka di tengah keberagaman ini organisasi diharapkan membingkai praktek yang akan memuaskan kelompok dan bukan hanya individu. Organisasi harus mampu mengidentifikasi dan mengevaluasi motivasi internal maupun eksternal yang diperoleh seorang karyawan dari kepuasan kerja dan selanjutnya meningkatkannya dengan motivasi eksternal sesuai kebutuhan sehingga organisasi dapat memperhatikan teori motivasi (Varma, 2017). Pekerjaan yang dilaksanakan secara sungguh-sungguh akan menghasilkan kinerja yang baik. Oleh sebab itu motivasi penting dalam meningkatkan kinerja karyawan.

Indikator motivasi adalah sebagai berikut (Varma, 2017): 1) Pelatihan dan pengembangan, adanya pelatihan guna meningkatkan kemampuan kerja. 2) Peluang peningkatan karir, adanya peluang untuk berkembang sehingga tidak stagnan. 3) Kerjasama tim, adanya dukungan dari kelompok. 4) Kompensasi atau tunjangan, adanya kompensasi atau tunjangan dalam bekerja. 5) Sistem penghargaan finansial, adanya penghargaan untuk kinerja baik. 6) Pengakuan dan apresiasi, adanya apresiasi dari atasan dalam bekerja 7) Keseimbangan kehidupan kerja, kesesuaian antara kemampuan dengan tanggung jawab yang diberikan.

Motivasi dan kepuasan kerja adalah faktor kuncinya untuk pencapaian kinerja jenis organisasi. Motivasi dan kepuasan kerja mempengaruhi pekerja untuk memastikan pemanfaatan maksimum upaya mereka untuk pencapaian tujuan organisasi (Rahman, Fatema, \& Ali, 2019).

Kepuasan kerja yang signifikan terkait dengan individu yang mendapatkan manfaat ekstrinsik dan intrinsik yang cukup untuk menginspirasi pekerja untuk tinggal dan terus menghabiskan sebagian besar waktu dan menyelesaikan tanggung jawab mereka (Ali, Bin, Piang, \& Ali, 2016). Perasaan puas bagi karyawan menimbulkan rasa ikhlas dalam bekerja sehingga akan sungguh-sungguh dalam 
bekerja. Keikhlasan dalam bekerja tentunya akan menghasilkan kinerja yang baik.

Indikator kepuasan kerja (Rahman et al., 2019): 1) Variasi keterampilan, yaitu memiliki berbagai macam keterampilan yang dapat menunjang pekerjaan, 2) Identitas tugas, yaitu adanya kejelasan mengenai tugas yang dibebankan. 3) Signifikansi tugas, yaitu tugas yang dikerjakan memberikan dampak pada perusahaan, 4) Otonomi, yaitu adanya wewenang dalam menyelesaikan tugas. 5) Umpan balik tugas, yaitu adanya evaluasi dari tugas yang diberikan.

\section{METODE PENELITIAN}

Penelitian ini merupakan penelitian kuantitatif yang menyajikan data secara statistika. Data dikumpulkan dengan menyebar kuisioner kepada responden. Analisis yang digunakan menggunakan analisis regresi berganda dimana analisis ini tujuannya menguji pengaruh antar variabel.

Objek penelitian ini adalah karyawan pemasaran perbankan syariah di Kabupaten Sumenep. Populasi keseluruhan karyawan bagian pemasaran perbankan syariah di Kabupaten Sumenep dengan teknik sampling yang digunakan adalah accidental sampling yaitu responden yang secara kebetulan ditemui oleh penulis sebanyak 32 karyawan yang ditemui.

\section{HASIL DAN PEMBAHASAN}

Analisis pertama adalah analisis deskriptif yang digunakan untuk menggolongkan responden.

Tabel 1. Distribusi Frekuensi

\begin{tabular}{llcc}
\hline & Kategori & Frekuensi & \% \\
\hline \multirow{2}{*}{ Jenis Kelamin } & Laki-Laki & 17 & $53 \%$ \\
\cline { 2 - 4 } & Perempuan & 15 & $47 \%$ \\
\hline \multirow{2}{*}{ Usia } & $\leq 20$ Tahun & 13 & $41 \%$ \\
\cline { 2 - 4 } & $>20$ Tahun & 19 & $59 \%$ \\
\hline \multirow{2}{*}{ Gaji } & $\leq$ Rp 500.000 & 11 & $28 \%$ \\
\cline { 2 - 4 } & $>$ Rp 500.000 & 21 & $72 \%$ \\
\hline
\end{tabular}

Sumber: Data Primer, Diolah (2020)

Analisis yang kedua adalah uji penelitian. Hasil uji validitas adalah validitas variabel untuk mengukur sebagai berikut. instrumen yang digunakan dalam

Tabel 2. Uji Validitas

\begin{tabular}{|c|c|c|}
\hline Variabel & Indikator & Pearson Correlation \\
\hline \multirow[t]{6}{*}{ Motivasi } & $\mathrm{X} 1.1$ & $.593^{* *}$ \\
\hline & $\mathrm{X} 1.2$ & $.542^{* *}$ \\
\hline & $\mathrm{X} 1.3$ & $.516^{* *}$ \\
\hline & $\mathrm{X} 1.4$ & $.466^{* *}$ \\
\hline & $\mathrm{X} 1.5$ & $.398^{*}$ \\
\hline & $\mathrm{X} 1.6$ & $.395^{*}$ \\
\hline
\end{tabular}




\begin{tabular}{lll}
\cline { 2 - 3 } Kepuasan & X1.7 & $.373^{*}$ \\
\cline { 2 - 3 } & $\mathrm{X} 2.1$ & $.403^{*}$ \\
\cline { 2 - 3 } & $\mathrm{X} 2.2$ & $.414^{*}$ \\
\cline { 2 - 3 } & $\mathrm{X} 2.3$ & $.407^{*}$ \\
\cline { 2 - 3 } Kinerja & $\mathrm{X} 2.4$ & $.374^{*}$ \\
\cline { 2 - 3 } & $\mathrm{X} 2.5$ & $.391^{*}$ \\
\cline { 2 - 3 } & $\mathrm{Y} 1.1$ & $.729^{* *}$ \\
\cline { 2 - 3 } & $\mathrm{Y} 1.2$ & $.760^{* *}$ \\
\hline & Y1.3 & $.817^{* *}$ \\
\hline & Y1.4 & $.828^{* *}$ \\
\hline
\end{tabular}

Sumber: Data Primer, Diolah (2020)

Analisis selanjutnya adalah uji variabel penelitian reliabel. Hasil uji reliabilitas dimana kriteria uji reliabilitas reliabilitas adalah sebagai berikut: apabila nilai cronbach's alpha $>0.7$ maka

Tabel 3. Uji Reliabilitas

\begin{tabular}{|c|c|c|}
\hline Variabel & Cronbach's Alpha & Keterangan \\
\hline Motivasi & .872 & Reliabel \\
\hline Kepuasan & .967 & Reliabel \\
\hline Kinerja & .780 & Reliabel \\
\hline
\end{tabular}

Sumber: Data Primer, Diolah (2020)

Analisis selanjutnya adalah uji nilai pada tabel coefficients regresi sederhana yaitu untuk menguji signifikansinya $<0,05$. Hasil pengujian pengaruh antar variabel penelitian. antar variabel adalah sebagai berikut:

Variabel berpengaruh signifikan apabila

\section{Tabel 4. Uji Regresi Sederhana}

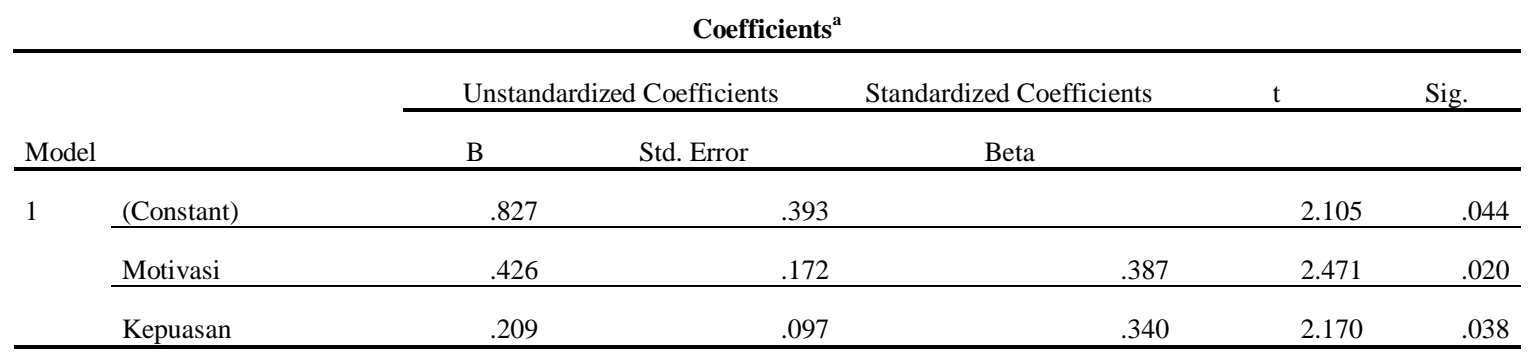

a. Dependent Variable: Kinerja

Sumber : Data Primer, Diolah (2020)

Analisis selanjutnya adalah uji nilai pada tabel coefficients regresi berganda yaitu untuk menguji signifikansinya $<0,05$. Hasil pengujian pengaruh antar variabel penelitian. antar variabel adalah sebagai berikut: Variabel berpengaruh signifikan apabila 
Tabel 5. Uji Regresi Berganda

ANOVA $^{\mathrm{a}}$

\begin{tabular}{|c|c|c|c|c|c|c|}
\hline \multicolumn{2}{|c|}{ Model } & \multirow{2}{*}{$\begin{array}{r}\text { Sum of Squares } \\
7.985\end{array}$} & \multirow{2}{*}{ df } & \multirow{2}{*}{$\begin{array}{r}\text { Mean Square } \\
3.993 \\
\end{array}$} & \multirow{2}{*}{$\begin{array}{l}\mathrm{F} \\
7.087\end{array}$} & \multirow{2}{*}{$\begin{array}{ll}\text { Sig. } & \\
& .003^{\mathrm{b}} \\
\end{array}$} \\
\hline 1 & Regression & & & & & \\
\hline & Residual & 16.337 & 29 & .563 & & \\
\hline & Total & 24.322 & 31 & & & \\
\hline
\end{tabular}

Sumber : Data Primer, Diolah (2020)

Hasil analisis deskriptif menunjukkan bahwasanya karyawan lakilaki lebih banyak dibandingkan perempuan dengan perbandingan 17:15. Sedangkan karyawan dengan usia dibawah 20 tahun lebih sedikit dibandingkan karyawan dengan usia diatas 20 tahun dengan perbandingan 13:19. Kemudian karyawan dengan gaji dibawah 500 ribu lebih sedikit dibandingkan dengan karyawan dengan gaji diatas 500 ribu dengan perbandingan 11:21.

Hasil uji validitas menunjukkan bahwasanya keseluruhan instrumen penelitian menunjukkan hasil yang valid. Dapat dilihat pada hasil luaran analisis data menunjukkan hasil $>0,3$. Sedangkan hasil uji reliabilitas menunjukkan bahwasanya keseluruhan variabel dalam penelitian adalah reliabel. Hal tersebut dapat dilihat hasil luaran analisnya $>0,7$.

Hasil uji regresi masing-masing variabel menunjukkan bahwasanya motivasi berpengaruh positif dan signifikan terhadap kinerja. Dapat dilihat dimana nilai t-statistik $>1,96$ dan $p$-value $<0,05$. Motivasi berpengaruh positif dan signifikan terhadap kinerja sesuai dengan penelitian dari Adam \& Kamase (2019); Cong \& Van (2013); Ghaffari, Burgoyne, \& Nazri (2017); (Dobre, 2013). Semakin tinggi motivasi yang diberikan oleh perusahaan maka semakin baik pula kinerjanya.

Variabel kepuasan berpengaruh positif dan signifikan terhadap kinerja. Dapat dilihat dimana nilai t-statistik $>1,96$ dan p-value $<0,05$. Kepuasan berpengaruh positif dan signifikan sesuai dengan penelitian Kavita, Simran, Pramod, Lalit, \& K (2012); Vrinda \& Jacob (2015); Ouedraogo \& Leclerc (2013); Destari, Lumbanraja, \& Absah (2018).

Hasil uji regresi berganda menunjukkan bahwasanya kepuasan dan motivasi berpengaruh positif dan signifikan terhadap kinerja. Dapat dilihat bahwasanya hasil signifikansinya $<0,05$ sehingga menunjukkan keduanya signifikan terhadap kinerja. Hasil penelitian ini sesuai dengan penelitian dari Bernanthos (2018); Cong \& Van (2013); Rahman et al., (2019); (Lut, 2012).

\section{KESIMPULAN}

Motivasi berpengaruh positif dan signifikan terhadap kinerja. Semakin baik motivasi ataupun rangsangan dari perusahaan agar karyawan mengeluarkan segala kemampuannya maka semakin baik dampaknya pada kinerja karyawan. Kepuasan berpengaruh positif dan signifikan terhadap kinerja. Semakin puas karyawan terhadap apa yang didapat dari perusahaan baik perlakuan maupun 
penghargaan maka akan berdampak pada baiknya kinerja. Motivasi dan kepuasan berpengaruh positif dan signifikan terhadap kinerja. Masing-masing variabel memiliki pengaruh yang positif dan signifikan terhadap kinerja. Gabungan dari keduanya yaitu motivasi dan kepuasan pastinya akan mempengaruhi kinerja yang baik pula. Motivasi yang diberikan dan kepuasan yang dirasakan oleh karyawan terhadap perusahaan akan berdampak pada baiknya kinerja karyawan.

\section{DAFTAR PUSTAKA}

Adam, F., \& Kamase, J. 2019. The effect competence and motivation to satisfaction and performance. International Journal of Scientific and Technology Research, 8(3), 132140.

Ali, A., Bin, L. Z., Piang, H. J., \& Ali, Z. 2016. The Impact of Motivation on the Employee Performance and Job Satisfaction in IT Park (Software House) Sector of Peshawar, Pakistan. International Journal of Academic Research in Business and Social Sciences, Human Resource Management Academic Research Society, 6(9), 297-310.

Aryanta, I. K., Sitiari, N. W., \& Yasa, P. N. S. 2019. Influence of Motivation on Job Stress, Job Satisfaction and Job Performance at Alam Puri Villa Art Museum and Resort Denpasar. Jurnal Ekonomi \& Bisnis JAGADITHA, 6(2), 113-120.

Bernanthos, B. 2018. The Direct and Indirect Influence of Leadership, Motivation and Job Satisfaction Against Employees' Performance. European Research Studies Journal, 21(2), 236-243.

Bhatti, M. I., Awan, H. M., \& Razaq, Z. 2014. The key performance indicators (KPIs) and their impact on overall organizational performance. Quality and Quantity, 48(6), 31273143.

Cong, N. N., \& Van, D. N. 2013. Effects of Motivation on Employees' Performance at Petrovietnam Nghe An Construction Joinst Stock Corporation. American Journal of Business and Management, 2(2), 212-217.

Destari, Y., Lumbanraja, P., \& Absah, Y. 2018. The Influence of Work Satisfaction on Employees Performance with Organizational Commitment as Intervening Variable at Mining and Energy Agency of North Sumatera. International Journal of Scientific and Technology Research, 5(12), 355-364.

Dobre, O. 2013. Employee motivation and organizational performance. Review of Applied Socio-Economic Research, 5(1), 53-60.

Ghaffari, S., Burgoyne, J., \& Nazri, M. 2017. The Influence of Motivation on Job Performance: A Case Study at Universiti Teknologi Malaysia. Australian Journal of Basic and Applied Sciences, 11(4), 92-99.

Jr, R. J. 2016. Job Performance , Job Satisfaction and Motivation: A Critical Review of Their Job Performance, Job Satisfaction, and Motivation: A Critical Review of their Relationship. International Journal of Advances in Management and Economics, (December), 36-43.

Kavita, G., Simran, K., Pramod, G., Lalit, J., \& K, S. S. 2012. Impact of Job Satisfaction on Employee Performance, a Challenge for HR Managers in Changing Environment. International Journal of Scientific Research and Reviews, 1(3), 88-95.

Kelimeda, Hairudinor, Ridwan, M. N. I., \& Dalle, J. 2018. European Journal 
of Human Resource Management Studies The Effect of Motivation, Job Satisfaction and Job Discipline Toward Employee Performance of PT. Buma Perindahindo at Lng Tangguh Site,. European Journal of Human Resource Management Studies, 2(1), 49-73.

Lut, D. M. 2012. Connection between Job Motivation, Job Satisfaction and Work Performance in Romanian Trade Enterprises. Annals of Dunărea de Jos University. Fascicle I: Economics and Applied Informatics, (3), 45-50.

Ouedraogo, A., \& Leclerc, A. 2013. Job satisfaction and organizational performance: Evidence from canadian credit union. Journal of Organizational Culture, Communications and Conflict, 17(1), 35-50.

Palar, A. 2016. The Effect of Work Motivation and Job Satisfaction on Employee Performance At Bank Sulutgo Tomohon. Jurnal Berkala Ilmiah Efisiensi, 16(3), 562-572.

Pang, K., \& Lu, C. S. 2018. Organizational motivation, employee job satisfaction and organizational performance: An empirical study of container shipping companies in Taiwan. Maritime Business Review, 3(1), 36-52.

Rahman, M. H., Fatema, M. R., \& Ali, M. H. 2019. Impact of Motivation and Job Satisfaction on Employee's Performance: An Empirical Study. Asian Journal of Economics, Business and Accounting, (March 2019), 1-10.
Saryadi, \& Arini, L. D. D. 2019. Competence, Motivation on Performance of Nursing: The Mediating Effect of Satisfaction. Icohetech 2019, 10-14.

Varma, C. 2017. Importance of Employee Motivation \& Job Satisfaction for Importance of Employee Motivation \& Job Satisfaction for Organizational Performance. International Journal of Social Science \& Interdisciplinary Research, 6(2), 10-20.

Vrinda, N. N., \& Jacob, N. A. 2015. the Impact of Job Satisfaction on Job Performance. International Journal in Commerce, IT \& Social Sciences, 2(2), 27-37. 